\title{
A AUTONOMIA PRIVADA DO PACIENTE DEPENDENTE DE SUBSTÂNCIA NO BRASIL E A DISCUSSÃO SOBRE A INTERNAÇÃO INVOLUNTÁRIA
}

\author{
THE PRIVATE AUTONOMY OF SUBSTANCE DEPENDENT PATIENTS IN \\ BRAZIL AND A DISCUSSION ON INVOLUNTARY INTERMENT
}

\author{
Joyceane Bezerra de Menezes ${ }^{1}$ \\ Wagner Pinheiro Gesser ${ }^{2}$
}

\begin{abstract}
RESUMO - Desenvolve uma discussão no plano da bioética e do direito de personalidade, com o fim de analisar o conflito entre a autonomia privada do paciente dependente de substâncias e a atuação do médico na definição do tratamento, especialmente da internação involuntária. Adota uma metodologia de abordagem qualitativa, mediante pesquisa bibliográfica de análise doutrinária e documental. Entende-se, com a análise, que o diagnóstico da dependência de substância não é condição exclusiva e suficiente para que o médico imponha a internação involuntária. Há que se observar a vontade do paciente, em atenção à sua autodeterminação. Na medida em que persistir, com juízo crítico, opondo-se à medida interventiva, a vontade do dependente prevalecerá sobre o interesse da família e/ou de terceiros. Isto em razão da cláusula geral de tutela, constitucionalmente consubstanciada no princípio da dignidade da pessoa humana e no direito geral de liberdade, também assentado como princípio constitucional.
\end{abstract}

PALAVRAS-CHAVE - Autonomia privada. Transtorno de dependência a substâncias. Deontologia médica.

ABSTRACT - A discussion relating to bioethics and personal rights is developed, towards analyzing the conflict between the private autonomy of the substance dependent patient and medical action, in defining treatment and specially determining involuntary interment. A qualitative methodology is adopted through bibliographical research of documents and analyses of doctrine. Through this analysis, it is understood that substance dependence is not in itself a exclusive or sufficient condition to warrant a doctor imposing an involuntary interment. While sufficient critical judgment is present in patient, the dependent's decisions prevail over those of family or third parties. This is so in light of the general clause of 'tutela', constitutionally supported by the principal of the dignity of human beings and the general right to liberty, another constitutional principal.

KEYWORDS - Private autonomy of will. Substance dependence disorder. Medical deontology.

\footnotetext{
1 Doutora em Direito pela Universidade Federal de Pernambuco. Mestre em Direito pela Universidade Federal do Ceará. Professora adjunto da Universidade de Fortaleza. Programa de Pós-Graduação Stricto Senso em Direito (Mestrado/Doutorado) da Universidade de Fortaleza, na Disciplina de Direitos de Personalidade. Professora adjunto da Universidade Federal do Ceará. Email: joyceane@unifor.br.

${ }^{2}$ Médico psiquiatra. Membro da Associação Brasileira de Psiquiatria.Especialista em Saúde Mental, pela Universidade Federal do Piauí. Especialista em Dependência Química pela Universidade Federal de São Paulo. E-mail: wpgesser@uol.com.br
} 


\section{CONSIDERAÇÕES INICIAIS}

A prática diária na psiquiatria leva o profissional, na maioria das vezes, a difícil tarefa de compatibilizar o respeito à autonomia privada do paciente e o tratamento psiquiátrico. A reforma psiquiátrica no Brasil traz normas que intentam regular as principais situações em que este conflito é mais premente, como na hipótese de internação involuntária.

Primariamente, importa destacar que o paciente portador de dependência química é um ser humano, dotado de direitos e titular de uma dignidade a ser considerada. Mesmo no estado de saúde psíquica comprometido, é necessário acatar os efeitos de sua autodeterminação. Logo, a intervenção do médico terá limite na autonomia privada do sujeito paciente, de modo a respeitar-Ihe os direitos de personalidade.

A questão se complica naquelas situações em que o estado do paciente o expõe moralmente, põe em risco a sua saúde ou a saúde de terceiros. É certo que, as normas do controle social regulam a atuação lesiva da pessoa. Mas a pergunta é: como o médico deve agir em face do paciente que necessita de tratamento e se recusa a recebê-lo. Poderia impor-lhe um tratamento, até mesmo determinando-Ihe a internação involuntária? A análise deste texto se concentra na atuação do médico psiquiatra diante do paciente portador de dependência química, com o fim de perscrutar os limites da sua atuação profissional diante da autonomia privada do seu paciente dependente químico.

O atual Código Civil Brasileiro prevê a perda relativa da capacidade para o toxicômano e alcoólatras, após o devido processo legal de interdição. Porém, muitas são as outras situações em que o dependente de substância chega a um estágio grave de comprometimento cognitivo, sem que haja sofrido qualquer restrição judicial à sua capacidade civil.

Para a análise destas questões, o texto se divide em duas partes: a primeira faz uma abordagem perfunctória sobre a reforma psiquiátrica no Brasil e a legislação em deontologia médica, enquanto que a segunda parte dispõe sobre a autonomia do paciente na aprovação do tratamento médico. Inicia-se o artigo com uma reflexão sobre a relação entre ética e a lei. $E$ após, apresenta a evolução do direito da personalidade no Brasil, como o processo que motiva a 
reforma psiquiátrica, enfocando os aspectos relativos à volição e a autodeterminação do paciente.

\section{A REFORMA PSIQUIÁTRICA NO BRASIL E AS MODALIDADES DE INTERNAÇÃO}

Em nível internacional, o modelo assistencial e comunitário de saúde mental vem se sobrepondo ao modelo hospitalar, genericamente ligado às instituições psiquiátricas de características asilares e custodiais. Em função da ascendência e fortalecimento das doutrinas humanistas e, conseqüentemente, dos direitos humanos, a atenção à saúde mental tem prosperado para ampliar o respeito à personalidade e à dignidade do indivíduo. $\mathrm{O}$ objetivo é por abaixo todas as reminiscências das antigas práticas cartesianas, marcadas pela negação da loucura, conforme descreve Foucault (2004). Até um passado não tão distante, a loucura e outras formas de transtornos mentais eram tratados apenas em vista da tutela da família, da segurança e da propriedade, priorizando-se as instituições em detrimento da pessoa ${ }^{3}$.

Apesar das dificuldades em oferecer um conceito para doença mental e para transtorno de comportamento, em face dos critérios que oscilam nas diferentes épocas, conforme o ritmo de trabalho e outras fontes de estresse que, findam por desenhar novas formas de perturbações psíquicas, o Conselho da Europa reconheceu que as atitudes de respeito ao portador da doença mental evoluíram na segunda metade do século XX.

Já em 1990, o Brasil adotava a Declaração de Caracas (1990), marco dos processos de reforma da assistência em Saúde Mental nas Américas. Esta Declaração enfatizava, entre outros pontos, um modelo baseado no Atendimento Primário da Saúde, centrado na comunidade e dentro de suas redes sociais;

\footnotetext{
${ }^{3}$ Cunha Rodrigues (2000, p.21) ressalta que "Na Renascença, a loucura ainda é analisada segundo o ângulo da transcendência: instala-se nos confins do mundo, do homem e da morte como figura escatológica. Se é verdade que, com Erasmo, o humanismo, entrou, cada vez mais, no discurso da loucura, a carga de tragédia aparece em Bosch ou Brueghel e subsiste, no imaginário colectivo, como uma espécie de nave, em que rostos distorcidos pela angústia e pelo terror retratam paisagens que falam da estranha alquimia entre os saberes, as surdas ameaças de bestialidade e o fim dos tempos. A institucionalização do internamento data do século XVII. Os insensatos, os homossexuais, as viúvas que se "casam tolamente", ou os filhos-família que querem contrair "um casamento vil", os pobres e os vagabundos são internados em prisões e hospitais. A loucura é assimilada ao crime e retribuída como castigo".
} 
numa revisão crítica do papel hegemônico e centralizador do hospital psiquiátrico na prestação de serviços; e no emprego dos recursos, cuidados e tratamentos para a salvaguarda da dignidade pessoal e dos direitos humanos e civis (VENTURA, 2007, p.834).

Em 17 de dezembro de 1991, a Assembléia Geral das Nações Unidas aprovou os princípios gerais destinados à proteção da pessoa atingida por doença mental, reconhecendo-Ihes alguns direitos que se assentam, inexoravelmente, no respeito a sua dignidade, dentre os quais: o acesso aos melhores cuidados de saúde mental disponíveis; a humanidade do tratamento, mediante o respeito à dignidade da pessoa humana; a proteção contra todas as formas de exploração, seja econômica, sexual, etc; a não discriminação; o reconhecimento dos direitos civis, políticos, econômicos, sociais e culturais, atribuídos por instrumentos internacionais; o direito de defesa e de acesso aos tribunais; e ainda o direito à vida comunitária e ao trabalho, se possível.

Instituíram-se princípios que primam pela vida comunitária e expurgam as formas de tratamento pautadas no alijamento social. O internamento forçado passou a sofrer severas restrições.

A própria compreensão de doença mental sofreu alterações. Ao passo que o cenário da vida moderna, com sua elevada carga de stress, contribuiu para a ocorrência de outras formas de perturbações psíquicas merecedoras de atenção, posto que ofensivas à saúde mental.

A Lei oㅜ 10.216, de 6 de abril de 2001 (BRASIL, 2004, p.17) dispõe sobre a proteção e os direitos das pessoas portadoras de transtornos mentais, adotando um modelo assistencial comunitário em saúde mental. Opta-se pela internação apenas nos casos em que os recursos extra-hospitalares não se mostrarem suficientes, sendo vetada a utilização de instituições asilares. Por esta razão, o tratamento em regime de internação será estruturado de forma a oferecer assistência integral à pessoa portadora de transtornos mentais, incluindo serviços médicos, de assistência social, psicológicos, ocupacionais, de lazer, e outros.

A internação tem como fim permanente, a reinserção do paciente ao seu meio de convívio e somente se realizará por meio de laudo médico circunstanciado que caracterize os motivos da medida.

A Lei prevê três tipos de internação psiquiátrica: a internação voluntária, 
que conta com o consentimento do paciente; a internação involuntária que se dá a pedido de terceiro, mas sem o consentimento do paciente; e a internação compulsória que é determinada pelo Estado, por meio do Poder Judiciário. Tanto a internação voluntária quanto a internação involuntária exigem a autorização de médico registrado no Conselho Regional de Medicina do Estado onde se situa o estabelecimento hospitalar. Mas devem ser atendidos requisitos legais específicos que, objetivamente, procuram preservar a personalidade do paciente e a sua autonomia.

A internação psiquiátrica voluntária (IPV) depende da manifestação volitiva expressa do paciente, mediante declaração assinada no ato de sua admissão, na qual conste que optou por aquela modalidade de tratamento. Em conseqüência, o término da internação se dará não somente por determinação do médico assistente, mas também por solicitação do paciente, conforme estabelece o art. $7^{\circ}$. da lei acima mencionada. Nota-se, nesta modalidade de internação, há o respeito absoluto à autonomia do paciente. Isto porque ainda é portador de juízo crítico e volição que lhe permitam uma escolha consciente. Entretanto, se o médico perceber a necessidade de prolongar o tratamento e diagnosticar 0 prejuízo do sistema volitivo do paciente, a internação voluntária pode se transformar em internação involuntária, o que torna relativiza o respeito à sua autonomia.

A internação psiquiátrica involuntária (IPI) exige tanto na internação quanto na alta, a comunicação ao Ministério Público Estadual da circunscrição territorial do estabelecimento, no prazo de setenta e duas horas após a adoção da medida. Este dispositivo também se aplicará aos casos em que uma IPV se converter em IPI.

Como a própria locução explica, a Internação Psiquiátrica Involuntária prescinde do consentimento do paciente que é apresentado ao médico por familiar ou responsável legal ou até mesmo por alguma autoridade legal (policia civil ou militar, bombeiro etc), comum quanto aos andarilhos ou moradores de rua, sozinhos. Por se tratar de uma medida, em princípio ofensiva à autodeterminação, o médico haverá que analisar detidamente a sua necessidade, avaliando ainda, se o paciente, de fato está com prejuízo em sua capacidade de juízo crítico. $O$ Diretor da Clínica Psiquiátrica dos Hospitais da Universidade de Coimbra diz que, 
naquela unidade, a internação involuntária não chega a atingir 1\% (um porcento) do total das internações psiquiátricas (SERRA, 2000, p.56). No Brasil, a média certamente supera esse percentual.

A IPI tem merecido atenção redobrada após a Reforma Psiquiátrica no Brasil. Certamente esses cuidados são reflexos do princípio da dignidade da pessoa humana que sustenta a luta e o fortalecimento das doutrinas humanistas. Como também é uma resposta às medidas autoritárias e abusivas que alijaram pessoas do convívio social por anos, aniquilando a sua própria condição de ser humano.

A Portaria GM n.2.391, de 26 de dezembro de $2002^{4}$ (BRASIL, 2004, p.166), estabelece o controle das internações psiquiátricas involuntárias (IPI) e voluntárias (IPV), regulamentando o disposto na Lei ํㅜ 10.216, de 6 de abril de 2002, e apresenta os procedimentos de notificação e comunicação das IPI e IPV ao Ministério Público pelos estabelecimentos.

Estabelece também que o gestor estadual do Sistema Único de Saúde SUS constituirá uma comissão Revisora das Internações Psiquiátricas Involuntárias, com a participação de integrante designado pelo Ministério Público Estadual, incumbido do acompanhamento dessas internações, após o recebimento da comunicação pertinente. Mas, até hoje, nem todos os Estados brasileiros tem estas comissões estruturadas e operantes.

Em acordo com a norma, essa comissão deverá ser multiprofissional, sendo composta de, no mínimo, um psiquiatra ou clínico em geral, com habilitação em Psiquiatria, e um profissional de nível superior da área de Saúde Mental, não pertencentes ao corpo clínico do estabelecimento onde ocorrer a internação, além de representante do Ministério Público Estadual. É relevante e desejável que dela também façam parte, representantes de associações de direitos humanos ou de usuários de serviços de saúde mental e familiares. Poderão ser constituídas, Comissões Revisoras das Internações Psiquiátricas Involuntárias, em âmbito microrregional, municipal ou por regiões administrativas de municípios de grande porte.

Como fiscal da lei e tutor dos interesses sociais, o Ministério Público poderá solicitar informações complementares ao médico responsável pelo laudo

\footnotetext{
${ }^{4}$ Gabinete do Ministro da Saúde.
} 
e/ou à direção do estabelecimento, assim como entrevistar o próprio internado, seus familiares ou a quem julgar conveniente. E ainda, entendendo necessário, autorizar a outros especialistas a examinar o internado, com vistas a obtenção de parecer escrito que venha a ratificar ou contrapor o laudo inicial.

Como uma forma de evitar que a internação se converta numa espécie de alijamento social perpetuo ou de tempo indeterminado, a Comissão Revisora efetuará, até o sétimo dia da internação psiquiátrica involuntária (IPI), a sua revisão, emitindo laudo de confirmação ou de suspensão do regime de tratamento adotado, com remessa de cópia ao estabelecimento de saúde responsável pela internação, no prazo de vinte e quatro horas.

A última modalidade de internação é a Internação Psiquiátrica Compulsória (IPC) que, nos termos da legislação vigente, somente poderá ser determinada pelo Poder Judiciário, em atenção às condições de segurança do estabelecimento quanto à proteção do paciente, dos demais internados e dos funcionários. É bem certo que a medida judicial dependerá do devido processo legal, no qual não se dispensará o parecer técnico do profissional competente.

\section{A DEONTOLOGIA MÉdICA: O PODER/DEVER DO MÉdICO NAS HIPÓTESES DE INTERNAÇÃO PSIQUIÁTRICA INVOLUNTÁRIA}

O Código de Ética Médica estabelece que o alvo da atuação do médico é a saúde do ser humano, em função da qual empenhará todo o seu zelo e capacidade profissional. É seu dever, o respeito absoluto pela vida humana e a agir sempre em benefício do paciente. Não poderá, nos termos da deontologia médica, utilizar os seus conhecimentos para gerar sofrimento físico ou moral, para o extermínio do ser humano ou para permitir e acobertar tentativa contra sua dignidade e integridade. Mas é seu dever indicar o procedimento adequado ao paciente, observadas as práticas reconhecidamente aceitas e respeitando as normas legais vigentes no País, nos termos do art. 22, do Código de Ética Médica.

Tem-se aqui, o dever do médico em respeitar a dignidade do seu paciente e, conseqüentemente, a sua autodeterminação ético-existencial. O dever de envidar esforços para a preservação ou recuperação da saúde do paciente, sem 
se sobrepor a sua vontade e autodeterminação. Por esta razão the é defeso realizar qualquer procedimento sem o consentimento e esclarecimento prévios ao paciente ou responsável legal.

Em razão do dever de respeito à integridade da pessoa, o médico não poderá adotar práticas que provoquem a alteração da sua personalidade ou da sua consciência, com o fito de reduzir-lhe a resistência física ou mental em investigação policial ou de qualquer outra natureza. Responderá civil, penal e administrativamente por seus atos lesivos à personalidade e à saúde física e/ou mental do paciente.

O próprio Código de Ética Médica traz o dever de respeito à personalidade e à integridade fisio-psíquica do paciente e as conseqüências decorrentes do seu descumprimento. No entanto, torna obrigatória a atuação impositiva do médico quando em face do iminente perigo de vida (art.56) ${ }^{5}$.

É fácil admitir-se a atuação impositiva do médico nas hipóteses em que o paciente não apresentar qualquer juízo crítico, discernimento ou livre e consciente manifestação volitiva. Aqui, prevalecerá a atuação profissional na tentativa de preservação da saúde e da vida da pessoa. Não há como se apurar a sua autonomia privada, posto que não há volição apta.

Inobstante, em se tratando de paciente portador de dependência química, haverá hipóteses em que o médico estará legitimado a aplicar um tratamento à revelia de sua vontade? Caberia, nos moldes da ética médica e da legislação brasileira, a internação psiquiátrica involuntária? Quais requisitos acompanhariam a opção por este procedimento?

Na hipótese de ausência de juízo crítico, nos casos de iminente perigo de vida, o Código de Ética Médica não só autoriza, mas impõem ao médico a obrigação de adotar medidas que afastem esse perigo. É necessário averiguar se o dependente de substância está sem juízo crítico e sob iminente perigo de vida. $\mathrm{Na}$ medida em que a ausência do discernimento está associada à ameaça a saúde e/ou vida de terceiros também seria razoável a medida. Mas nessa última hipótese, ainda há maior complexidade. Na medida em que o paciente apresenta comportamento violento e familiares se sentem ameaçados, caberia a aplicação

\footnotetext{
${ }^{5}$ RESOLUÇÃO CFM no 1.246/88 (Código de Ética Medica), Art. 56 - Desrespeitar o direito do paciente de decidir livremente sobre a execução de práticas diagnósticas ou terapêuticas, salvo em caso de iminente perigo de vida.
} 
da medida? Crê-se, nessa hipótese, que o médico terá maior responsabilidade na construção do laudo, haja vista que se apoiará em circunstâncias alheias ao mero exame clínico ${ }^{6}$. Cercado de todas as cautelas, mediante autorização de familiar ou responsável, poderá proceder a internação involuntária.

\section{A AUTONOMIA DO PACIENTE DEPENDENTE DE SUBSTÂNCIA}

Conforme Damásio "a autodeterminação (free will) é apenas um outro nome para a idéia de se escolher de acordo com resultados a longo prazo ao invés de a curto prazo"(DAMASIO, 1994).

Examinada sob uma perspectiva da neurociência atual (BURNS, 2007) pode-se entender, de uma maneira bastante simplificada, que a volição advém de uma interação de dois sistemas neurais individuais, interagentes: um sistema impulsivo e um sistema reflexivo. O sistema reflexivo controla o sistema impulsivo por meio de vários mecanismos de controle de impulso.

Assim, pode-se concluir que duas condições podem desequilibrar este sistema volitivo: a) um sistema reflexivo disfuncional ou, b) um sistema impulsivo hiperativo. Uma ou outra pode resultar em prejuízo à capacidade volitiva do sujeito.

Pesquisas têm demonstrado que, tanto as pessoas com dano neuronal às regiões cerebrais responsáveis pelo circuito reflexivo quanto os indivíduos com dependência a substância exibem padrões similares de comportamento relacionados a uma disfunção do sistema reflexivo. Dois aspectos são relevantes a esse tópico: (I) ambos os grupos apresentam negação ou ausência de noção de terem um problema (de sua condição patológica) e ainda (II) indivíduos em ambos os grupos tendem a agir de maneira a obter recompensas imediatas, mesmo sob o risco das conseqüências negativas desastrosas. Um exemplo disso está na mãe, dependente química, que opta por gastar o que lhe resta em um papelote de crack, em vez de adquirir alimento para o filho. Opta pela aquisição do que the trará a satisfação imediata a cumprir o dever ético de alimentar o filho.

\footnotetext{
${ }^{6}$ O problema é semelhante em Portugal, conforme se extrai da afirmação do Prof. Serra (2000, p.58) "a lei está pouco clara também quanto ao procedimento viável a tomar quando o indivíduo tem transtornos evidentes de comportamento, carece de internamento, não o aceita e não tem familiares próximos que determinem o internamento e o seguimento posterior".
} 
De maneira semelhante, tem-se demonstrado que os indivíduos com dependência de substâncias, têm uma hipersensibilização do sistema impulsivo, o que Ihes torna hiperativos a ponto de conseguirem se sobrepor ao efeito moderador do sistema reflexivo.

É necessária uma reflexão maior sobre o tema, com a cautela de não adotar os resultados destas pesquisas como uma verdade prima facie. Essa análise não representa um entendimento conclusivo ou final, mas apenas os resultados iniciais de pesquisas sobre o mecanismo volitivo humano, e em aspectos parciais. Um entendimento integral desse mecanismo teria de incluir os vários estados de humor, saúde e inserção ambiental pelos quais as pessoas perpassam. Assim como em outras áreas humanas, o mais correto seria entender a existência de um continuum entre a incapacidade volitiva e a capacidade total ao invés de esquema de tudo ou nada, de disfunção-saúde.

De tempos remotos, a sociedade em geral e, conseqüentemente, o mundo médico-legal, entendia os pacientes dependentes de substâncias como desprovidos de vontade própria em função dessa dependência. Tratavam a dependência química em semelhança aos outros transtornos mentais em geral, cerceando e limitando a autonomia do dependente. O próprio Código Civil Brasileiro, de 1916, incluía, no rol dos absolutamente incapazes, os "loucos de todos os gêneros", albergando nesta condição todos aqueles sujeitos que fugissem à compreensão da normalidade, dentre os quais, os dependentes de substância.

Impulsionado por ventos libertários das décadas finais do século findo, temse incorporado o entendimento legal de que o paciente dependente de substância mantem a sua autonomia privada, quando tem preservada a sua capacidade cognitiva. E, por isso, poderá exercer seu direito à recusa de tratamento e/ou internamento. Isso representa, repita-se, uma forte valoração à vontade do paciente pela contínua ascensão das correntes humanistas.

As pesquisas citadas levantam indagações relevantes sobre a volição e autonomia individual, em especial no paciente dependente químico. Sugerem que, mesmo não estando sobre influência de uma intoxicação direta pela substância, a mera condição de dependência de uma substância já poderia ser o suficiente para prejudicar, mínima ou parcialmente, a sua volição e a sua 
capacidade de auto-autodeterminação.

No direito brasileiro, a teoria geral da liberdade de ação sustenta a autonomia individual do sujeito deve ser mantida, exceto em casos ultraexcepcionais, de absoluta falta de discernimento. E, mesmo nestas hipóteses, a restrição à capacidade civil não deve ser integral. Na medida do possível, há que se resguardar-Ihe a possibilidade de praticar os atos ainda compatíveis com o seu discernimento. Isto porque, mesmo acometido por algum transtorno, o indivíduo persevera no direito ao desenvolvimento de sua personalidade, consectário da dignidade da pessoa humana.

O instituto da incapacidade civil foi construído para proteger as pessoas portadoras de "deficiência juridicamente apreciável" (PEREIRA, 2007, p.272). Nestes termos, a restrição à capacidade civil deve ser proporcional à deficiência de discernimento e aplicável apenas para resguardar o interesse da pessoa, nos restritos limites da lei ${ }^{7}$.

Ascensão (2000, p.191) também qualifica a interdição como uma alternativa extrema, para aquela deficiência mais grave que torna o sujeito inapto a governar a sua pessoa e os seus bens. Para os portadores de deficiências menos severas, o mecanismo da inabilitação para a prática daqueles atos parece mais adequado.

No Brasil, além da medida extrema de intervenção, há alternativas legais de tutela da pessoa privada de discernimento, a exemplo da nulidade e anulação de atos jurídicos ${ }^{8}$.

Relativamente ao processo de restrição da capacidade em vista da

\footnotetext{
${ }^{7}$ No Brasil não existe incapacidade de direito, pois todas as pessoas, a partir do seu nascimento, têm capacidade de direitos ou de aquisição de direitos (GONÇALVES, 2005, p.84). Há variação na capacidade de fato, ou seja, na capacidade pessoal de exercício de direitos, em razão de fatores como idade, saúde, desenvolvimento mental e intelectual. A lei estabelece a figura dos absolutamente incapazes e a figura dos relativamente incapazes. Para os primeiros impõe a total restrição à capacidade civil de exercício, enquanto para os segundos reconhece uma capacidade de exercício mitigada.

${ }^{8}$ O Tribunal de Justiça do Estado de São Paulo demonstra, na decisão abaixo, a possibilidade de nulidade de negócio jurídico celebrado por pessoa absolutamente incapaz, mesmo sem a prévia sentença de interdição, senão veja-se: Ementa: Busca e apreensão. Liminar deferida. Bem não localizado. Conversão em ação de depósito. Contrato de financiamento celebrado por pessoa absolutamente incapaz de exercer atos da vida civil. Decretação de nulidade que independe de sentença de interdição. Prova inequívoca da incapacidade do réu anterior à data do contrato. Eventuais momentos de lucidez que não afastam a incapacidade do agente. Ação julgada improcedente. Sentença mantida. Recurso improviso. Apelação Com Revisão 1115929008. Relator(a): Walter Cesar Exner. Órgão julgador: 32a Câmara de Direito Privado. Data do julgamento: 10/04/2008.
} 
deficiência total ou parcial do discernimento, a legislação brasileira orienta, historicamente ${ }^{9}$, a possibilidade de fixação dos limites da interdição pelo órgão julgador, abrindo flanco para mantença de alguma esfera de capacidade, antes da declaração de completa incapacidade. Essa orientação parece adequada à cláusula geral de tutela da pessoa, cujo objetivo macro é resguardar o processo de autoconstrução que decorre, especialmente da autodeterminação éticoexistencial.

$\mathrm{Na}$ dicção de Oliveira, a autonomia ético-existencial corresponde ao "conjunto de princípios materiais em que se enunciam as condições concretas da dignidade da pessoa humana [...]"(OLIVEIRA, 2002, p.96). Integra a autonomia privada, faculdade do agente em "praticar um ato jurídico, determinando-lhe 0 conteúdo, forma e efeitos" (AMARAL, 2000, p.338).

Assim, o direito geral de personalidade pode ser interpretado como um direito de autodeterminação ético-existencial que se materializa nas escolhas que o indivíduo vem a fazer. Por isso, a liberdade é peculiar ao desenvolvimento da personalidade, representa um pressuposto para a autodeterminação do sujeito na realização de suas potencialidades (GARCIA,2007, p.117). E a liberdade se explica pela ausência de impedimentos (DE CUPIS, 2008, p.25). Segundo Alexy (2008, p.234) o direito geral de liberdade estabelece o direito a que o Estado nãodificulte ou não-embarace o seu exercício. Portanto, na medida em o indivíduo tiver um mínimo discernimento para escolher entre a aceitação ou recusa de uma intervenção médica e/ou hospitalar, terá a liberdade de optar, deverá ser respeitado na sua decisão.

Ou seja, a autodeterminação quanto à opção pelo tratamento ou internação não pode ser cerceada pelo Estado ou pelo particular sob pena de prejuízo aos direitos de personalidade, da autonomia privada, do direito geral de liberdade. Porém, essa liberdade que dá azo à autodeterminação não poderá, como de resto os demais direitos, ser compreendida em termos absolutos. Algumas vezes, se sujeitará ao sistema de ponderação em face dos demais princípios. Se a pessoa ainda porta discernimento e comete atos que violam interesse e segurança de terceiros, o problema se converterá em questão de segurança pública e assim

${ }^{9}$ O Decreto no.24.559/34 já permitia esse entendimento. Atualmente, a matéria segue o rito estabelecido nos arts.1.177 e seguintes do Código de Processo Civil e algumas disposições da Lei de Registros Públicos (Lei no 6.015/73). 
deverá ser tratado. Na hipótese em que o paciente incorre em violência pela incapacidade de auto-controle em função da droga, é possível o diagnóstico de perda do juízo crítico, ainda que temporária, para prescrever a medida interventiva, ainda que involuntária.

Além da autodeterminação, o dependente químico também terá a garantia da integridade psicofísica em face da atuação do médico. A partir do princípio da dignidade da pessoa humana e dos direitos individuais à vida, à liberdade, à segurança, à propriedade, à intimidade, ao acesso à justiça e devido processo legal, bem como pelos direitos sociais à saúde, ao lazer, à maternidade, à infância, à moradia e alimentação, ao ressarcimento dos danos, o ordenamento constitucional se pode afirmar a integridade psicofísica do sujeito.

O Código Civil de 2002 garante a integridade psicofísica da pessoa, a partir do art.11, quando dispõe sobre os direitos de personalidade. $O$ respeito à integridade psicofísica resulta da cláusula geral de tutela da personalidade, fundamentada na quintessência constitucional que é o princípio da dignidade da pessoa humana ${ }^{10}$, cuja expansão alcança toda ordem infraconstitucional.

Os direitos de personalidade visam tutela da personalidade física, psíquica e moral dos indivíduos, cuja representação se faz pelos "bens inerentes à própria materialidade e espiritualidade de cada homem" (TEPEDINO, 2001, p.28).

A tecitura da Constituição pátria se firma na dignidade da pessoa humana cuja influência se percebe nos fundamentos e objetivos da República brasileira, bem como nos direitos fundamentais, individuais e sociais. De tudo se extrai "uma verdadeira cláusula geral de tutela e promoção da pessoa humana, tomada como valor máximo pelo ordenamento" (TEPEDINO, 2001, p.48).

E essa tutela geral não se materializa em um numero clausus de enunciados protetivos, mas oxigena toda a atuação do Estado e do particular no trato da pessoa, em suas mais diversas situações vivenciais. Transgride, se necessário, a dicotomia direito público versus direito privado. Supera a lógica dos direitos subjetivos, permitindo o reconhecimento de posições jurídicas diversas que cumpram o intento maior que é a preservação e promoção da dignidade.

\footnotetext{
${ }^{10}$ Na percepção de Dworkin (2004, p.333-334), a dignidade da pessoa humana leva à máxima de que não se devem tratar as pessoas de modo que, em sua cultura e em sua comunidade, se entenda como uma forma de desrespeito. Apesar da vasta literatura sobre o princípio da dignidade da pessoa humana, não haverá se tem um conceito completo e a priori, pois a expressão conduz elevada carga de elementos culturais e históricos que levam a cambiância do seu conteúdo.
} 
A dependência de substâncias é uma situação de vida que traz conseqüências negativas para a pessoa. Mas, não determina, ipso fato, a negação da autodeterminação do doente, a ponto de cassar-lhe a capacidade civil, exceto se confirmado o comprometimento do seu juízo crítico em tempo ulterior ao efeito imediato da droga, mediante devido processo legal. $\mathrm{E}$ mesmo nestas hipóteses, a solução não será tão simplista.

Em tese, o Direito garante a autonomia privada do indivíduo. Além dos limites impostos pela ordem pública e os bons costumes, "o exercício da autonomia privada, como manifestação humana que pretende produzir efeitos jurídicos, exige requisitos de validade, são eles: informação, discernimento e ausência de condicionamentos externos" (NAVES e SÁ, 2002, p.119). Em face da ausência do discernimento, a pessoa pode ter prejudicada a sua autonomia privada.

O dependente químico deve ser informado do seu diagnóstico, assim como de todos os dados relativos ao tratamento proposto, especialmente dos efeitos, positivos e negativos. Se, tem juízo crítico para avaliar todos os dados e formular a sua escolha, discernindo o que entende melhor para si, caberá ao médico acatar a sua vontade. É certo que essa volição do paciente deve está livre de qualquer condicionante externo como pressão familiares, a coação ou a ameaça, por exemplo. Senão não a manifestação volitiva vem eivada de vício, daí a necessidade de uma visão complexa por parte do médico.

\section{A INTERNAÇÃO VOLUNTÁRIA OU INVOLUNTÁRIA DE PACIENTES DEPENDENTE DE SUBSTÂNCIAS}

O médico, clínico em geral e, em especial, o médico psiquiatra, freqüentemente, se deparará com a solicitação de internação de um paciente dependente de substância, seja por ele próprio, por parentes, por responsáveis ou até mesmo por terceiros.

Quando a pessoa solicita a internação, há que se verificar a necessidade da medida. Mas quando a internação é solicitada por terceiros e o paciente dela discorda, o médico, como já visto, terá de avaliar se a recusa é fruto de uma escolha legítima, apurada em perfeito juízo crítico. Se o paciente não tiver 
discernimento, o profissional terá maior mobilidade na determinação da sua internação.

Juízo é uma operação intelectual exercida pelo pensamento reflexivo (lógico), embora outros processos cognitivos além da ideação (afetividade, inteligência, sensopercepção, volição), contribuam para o resultado final. No caso do paciente dependente de substância, alterações patológicas desses processos cognitivos, excetuando a volição, por efeito direto ou indireto da substância, podem conduzir a quadros clínicos de claro prejuízo (delírios e alucinações, rebaixamento de consciência, agitação psicomotora, etc.) que justifiquem intervenções impositivas no campo do seu desejo.

Em termos gerais, a situação ético-legal de um paciente dependente a substância pode se resumir a basicamente três hipóteses: I. paciente com volição claramente prejudicado (temporariamente ou permanentemente); II. paciente com volição preservado que solicita internamento ou tratamento; III. paciente com volição preservado que não deseja internamento ou tratamento.

As duas primeiras hipóteses não apresentam em si maiores dificuldades para a atuação profissional. Na primeira, uma volição claramente prejudicada resulta na limitação da autonomia do paciente, cabendo ao responsável legal o direito de decidir por ele. $\mathrm{Na}$ ausência de um responsável legal, recai sobre o médico atendente essa responsabilidade, daí a necessidade de cautela redobrada.

A segunda hipótese também apresenta uma situação simples. Concluindo pela volição preservada, tem-se um paciente com plena autonomia para decidir seus rumos, inclusive para escolher uma internação voluntária. Na prática, esta medida pode apresentar percalços institucionais, geralmente, ao arrepio da lei, pois algumas instituições exigem a presença de um 'responsável' para efetivar a internação. Ora, se a autonomia executiva do paciente é verificada, ele concorda com a internação que é a alternativa apresentada pelo médico, em que se justificaria a necessidade de um 'responsável'?

Grandes dificuldades e dúvidas residem na terceira hipótese, quando a atuação do médico se contrapõe à vontade do paciente. Infelizmente a medicina não dispõe de testes quantitativos ou objetivos aptos a mensuração do percentual 
da capacidade volitiva de determinado indivíduo. O médico deve guiar a sua conduta pelo bom senso, em busca de soluções que promovam o bem maior do paciente e da própria sociedade.

Nesta gangorra dos processos mentais entre o impulsivo incontrolável e a reflexão moderadora, há um precedente, mais aceito nos países ocidentais, de respeitar a autonomia do dependente de substâncias, com capacidade volitiva, acatando, inclusive, a sua recusa ao tratamento ou internação.

Na prática diária, os dependentes levados a uma unidade psiquiátrica, com o propósito de internação, apresentam-se sob efeito agudo da substância, síndrome de abstinência, intercorrência ou concomitância de outro transtorno mental grave, ou ainda com alterações metabólicas graves ou agitações psicomotoras, demonstrando clara incapacidade para o exercício de sua autonomia. Nesses casos, a internação é determinada, ainda que depois venha a ser suspensa, na medida em que o dependente recobrar a razão e discordar da medida.

Mas há uma minoria de casos em que o dependente não está sob efeito direto da substância, e se apresenta lúcido e coerente, sem indícios de sinais psicóticos. Em geral, conduzido à instituição por familiares, sob maior ou menor grau de coerção e, ao ser examinado se manifesta irredutivelmente contrário à internação. $\mathrm{O}(\mathrm{s})$ familiar(es) exige $(\mathrm{m})$ a internação, geralmente de forma extremamente enérgica. Diante do cenário belicoso formado, cabe ao profissional atuar eticamente, respeitando os desejos e preservando autonomia do paciente, mesmo ante as opiniões contrárias dos seus familiares. Uma obrigação invariavelmente difícil, mas juridicamente necessária.

Infelizmente o familiar anseia por uma medida objetiva capaz de suprimir o desconforto doméstico que a doença acarreta. Porém, o tratamento ao dependente químico não visa, em linha primária, uma solução familiar, mas a atenção ao dependente, cuja personalidade não pode ser desconsiderada.

\section{CONSIDERAÇÕES FINAIS}

O dependente de substância não perde o direito de autodeterminação apenas pelo fato do diagnóstico médico. Goza de todos os direitos fundamentais, 
tem preservados os direitos de personalidade e a sua capacidade civil para realizar escolhas e praticar os atos que lhe compete, na medida em que lhe resta o discernimento. Portanto, o diagnóstico de dependência de substância nunca será requisito suficiente e exclusivo para justificar a cassação do consentimento do paciente.

A ascensão dos direitos fundamentais e o respeito aos direitos de personalidade vem interferindo na disciplina da saúde mental, como um reflexo global do fortalecimento das correntes humanistas. A própria sociedade tem alterado a sua percepção sobre a loucura e admitido a inclusão de pessoas diferentes, evitando classificações estigmatizantes. Os tratamentos não intentam a retirada do paciente do convívio social e familiar, muito pelo contrário, devem favorecer as condições de convivência e interação social.

O dependente de substância que, na leitura do Código Civil de 1916, seria incluído entre os loucos de todos os gêneros, a ponto de sofrer o despautério de uma inimputabilidade, tem, atualmente, reconhecidos o seu potencial de desenvolvimento e sua plena capacidade. Na área da medicina, este mesmo dependente terá a sua autonomia preservada, podendo, inclusive, rejeitar qualquer modalidade de intervenção médica. No Direito, a regra geral é a preservação da capacidade de autodeterminação, e, mesmo nas hipóteses de interdição, a mantença de alguma capacidade civil, para evitar maior dano ou dano completo ao seu potencial de autodesenvolvimento.

Enfocando especificamente o binômio autodeterminação do dependente de substâncias e o poder interventivo do médico, tem-se que aquela deve ser preservada em atenção ao direito geral de personalidade. Apenas nas restritas hipóteses de perda do juízo crítico do paciente, o médico poderá impingir-lhe o tratamento adequado e emergencial à preservação de sua vida, saúde e bemestar. Para fundamentar esta decisão, deverá realizar não apenas acurado exame clínico do paciente, mas também analisar o entorno social e o contexto familiar em que se insere.

A internação involuntária exige, para sua regularidade, obediência aos critérios rígidos estabelecidos por lei e, para evitar o cárcere privado e alijamento social do paciente, está sujeita ao reexame e à revisão por comissão multidisciplinar. 
A transposição da teoria objetiva para a prática diária subjetiva, a avaliação dessa capacidade volitiva é bem difícil, especialmente em face da impossibilidade de quantificação. A atuação do profissional se consubstancia em um exercício de subjetivismo.

Pesquisas recentes, na área da neurociência, vêm permitindo vislumbrar alguns mecanismos, na forma de circuitos neuronais, de formação e operacionalização da volição. Embora o estágio atual de conhecimento ainda corresponda apenas à ponta do iceberg, certamente instiga a imaginação e a perspectiva que, destas pesquisas, advenham métodos quantitativos, precisos e objetivos, capazes de tornar a atuação do profissional médico mais eficaz no que toca ao respeito à autonomia privada de seu paciente.

\section{REFERÊNCIAS}

AMARAL, F. 2000. Direito civil: introdução. Rio de Janeiro: Renovar, 640 p.

ASCENSÃO, J.O. 2000. Direito civil teoria geral. Introdução, as pessoas e os bens. Vol.1, Coimbra: Coimbra Editora, $431 \mathrm{p}$.

BRASIL. 2004. Ministério da Saúde. Secretaria-Executiva. Secretaria de Atenção à Saúde. Legislação em saúde mental: 1990-2004 / Ministério da Saúde, Secretaria-Executiva, Secretaria de Atenção à Saúde. - 5. ed. ampl. - Brasília: Ministério da Saúde.

BURNS, K and BECHARA, A. 2007. Decision making and free will: a neuroscience perspective. Behav. Sci. Law 25:263-280. WileyInter Science.

DAMASIO, A. R. 1994. Descartes' error: emotion, reason, and the human brain. New York:Grosset-Putnam.

DWORKIN, R. 2003. Domínio da vida. Aborto, eutanásia e liberdades individuais. São Paulo: Martins Fontes, 362 p.

FOUCAULT, M. 2004. História da loucura na antiguidade clássica. São Paulo: Editora Perspectiva, $551 \mathrm{p}$.

GARCIA, E.C. 2007. Direito geral de personalidade no sistema jurídico brasileiro. São Paulo: Editora Juarez de Oliveira, 333 p.

NAVES, B.T.O. e SÁ, M.F.F. 2002. Da relação médico-paciente: dignidade da pessoa humana e autonomia privada. M.F.F. SÁ (Org.), Biodireito. Belo Horizonte: Del Rey, p.102-127.

OLIVEIRA, N.M.P. 2002. O direito geral de personalidade e a solução do 
dissentimento. Ensaio sobre um caso de constitucionalização do direito civil. Coimbra: Editora Coimbra, $255 \mathrm{p}$.

PEREIRA, C.M.S. 2007. Instituições de direito civil. Teoria geral de direito civil. Vol.1. Rio de Janeiro: Forense universitária, 718 p.

RODRIGUES, C. 2000. Sobre o estatuto das pessoas afectadas de anomalia psíquica. Centro de Direito Biomédico da Faculdade de Direito de Coimbra e Instituto de Medicina Legal de Coimbra (Org.), A lei de saúde mental e o internamento compulsivo. Coimbra: Editora Coimbra, p.19-52.

SERRA, A.V. 2000. Comentários críticos à lei de saúde mental. Centro de Direito Biomédico da Faculdade de Direito de Coimbra e Instituto de Medicina Legal de Coimbra (Org.), A lei de saúde mental e o internamento compulsivo. Coimbra: Editora Coimbra, p.53-60.

TEPEDINO, Gustavo. 2001. Temas de direito civil. Rio de Janeiro: Renovar, 521 p.

VENTURA, C.A.A. et. al. 2007. Psychiatric nursing care in brazil: legal and ethical aspects. Med Law (2007) 26:829-840. Yozmot.

Recebido para publicação: 26/05/2009

Aceito para publicação: 19/12/2012 